\title{
Where is Fisheries Science Heading - How Can Fish Stock Assessments be Improved?
}

\author{
Øyvind Ulltang \\ Department of Fisheries and Marine Biology \\ University of Bergen, HIB, N-5020 Bergen, Norway
}

\begin{abstract}
Much of the relevant knowledge gained from the enormous amount of research carried out in fish population dynamics remains unused in stock assessments and predictions. A main challenge is to utilize more effectively the increasing scientific knowledge of factors and relations influencing fish stock development, including effects of a varying physical environment and multispecies interactions. Present stock assessments are often characterized by a lack of search for causal relations and explanations, concentrating the effort on the technical/mathematical aspects of the predictions. Recent stock assessment reports are certainly more advanced from a statistical and analytical/mathematical point of view than older reports, but they often contain less natural science. In particular, "VPAtuning" procedures underestimate the value of critical discussion of basic biological assumptions and use of independent knowledge of fishing fleets and surveys.

Predictions should not be limited to the usual option tables, giving catches next year and stock size for the following year for a range of fishing mortalities. More research effort should be directed towards the problem of predicting long-term effects of various exploitation strategies and study effects of exploitation on not only stock size, but also on stock structure and resulting effects on stock dynamics and the stock's adaptation to a fluctuating environment.
\end{abstract}

Keywords: assessment, environment, multispecies interactions, stock predictions.

\section{Introduction}

Substantial research has in recent years been devoted to the question of how to handle the uncertainties in fish stock assessments and management. This is crucial for a precautionary approach to fisheries management. Less attention has been given to the question of how to reduce the uncertainties and thereby improve our ability to predict short and long-term consequences of different exploitation strategies. This is crucial for a better understanding of what constitutes sustainable fisheries and for harvesting the fish resources at a near-optimum level. There exist a lot of oceanographic and biological knowledge which is not effectively utilized in present stock assessments and predictions, and more research effort should be directed towards the question of how such knowledge may be better utilized for reducing the uncertainties and improving the scientific basis for fisheries management.

The aim of this paper is to lead the attention to some basic weaknesses in present fish stock assessments with respect to how scientific knowledge is utilized, and suggest some changes in contemporary trends for improving stock predictions. It will not in any sense be a complete review of the theme. The examples will be from the Northeast Atlantic, and especially from assessments of the Northeast Arctic cod stock, but it is suspected that the problems are of basically the same character in the NAFO area.

\section{Explanations and predictions in fisheries science}

In Ulltang (1998) the predictions in fisheries science and the explanations offered in relation to the state of biotic and abiotic factors were reviewed in a historical and epistemological perspective. It is noted that in a fishery management context, the emphasis is on predictions, while the kinds of possible predictions and their properties will be determined by the nature of our explanations of events in our 
environment. For example, if recruitment fluctuations can be explained by a spawning stock-recruitment relationship and sea temperature, this can be used for predicting recruitment; assuming that spawning biomass and temperature are known or can be predicted.

The kind of explanations that can be offered for events in nature reflects the state of scientific knowledge. Hierarchical levels of explanations can be considered, or there can be no explanation, which is not in need of a further explanation. If for example fish stock variability is explained by recruitment fluctuations, the next (higher) level is to ask for an explanation of these fluctuations. Moving to a higher level can increase, sometimes drastically, the predictive power of the theories. Studies for further explaining the recruitment fluctuations, studies of the effects of a fluctuating physical environment on fish population parameters and studies of multispecies interactions are examples of research areas where recent developments may give, and to some extent already have given, a new level of explanation which can be used in fish stock predictions. However, fish stock assessments are still mainly based on a lower level of explanations, not explaining the recruitment variations or the observed variations in parameters such as fish growth and age-at-maturity. Much of the relevant knowledge from the enormous amount of research which has been carried out in fish population dynamics remains unused in stock assessments and predictions.

\section{Unused knowledge in stock assessments}

Most fish stock assessments carried out by the International Council for the Exploitation of the Sea (ICES) are based on a so-called "dynamic pool model", where stock and catches are broken down by age groups. Stock history is traced by using Virtual Population Analysis (VPA) or analogous techniques (Pope, 1972; Ulltang, 1977; Pope and Shepherd, 1982; Deriso et al., 1985; Schnute, 1994) using estimated catchesby-age as input data. The mortality from other causes than fishing (natural mortality M) is usually assumed constant in these calculations, and this constant value is seldom based on a precise estimate. For calculating total stock and spawning stock biomasses, observed mean weights-at-age and maturity ogives are used, but often these are given as mean values over long periods. The VPA is calibrated to survey observations, tagging experiments and/or commercial catch per unit of effort (CPUE) data by what are called "VPA-tuning" programs (which will be commented upon in a section below). Stock predictions are carried out by taking the VPA estimated stock size for the last year as a starting point. Estimates of target and limit reference points are calculated using average levels of the estimated vital parameters. The whole process is often referred to as analytical stock assessment.

The quality of stock predictions depends both on the VPA estimated stock size for the last year and the possibilities for predicting recruitment and year to year changes in growth and natural mortality. Unused knowledge in VPA tuning procedures and stock predictions can be listed as:

- Information on varying distribution of the stock between years induced by, for example, varying oceanographic conditions (which could influence the various abundance indices to a variable extent),

- Information on varying levels of predator stocks or alternative prey stocks (which could render the assumption of constant natural mortality in VPA tuning and predictions invalid), and knowledge about relationships which can be used for estimating the resulting predation (including cannibalism) mortality (Bogstad et al., 1994; Nilssen et al., 1994; Barros, 1995; Ulltang, 1996),

- Knowledge about food consumption as a function of temperature (Bogstad and Gjøsæter, 1994),

- Knowledge about environmental effects on survival (Shepherd et al., 1984; Sætersdal and Loeng, 1987; Ellertsen et al., 1989; Dickson et al., 1994; Ottersen et al., 1994; Ottersen and Sundby, 1995),

- Knowledge about relationships determining population fecundity (total egg production, which may not be proportional to biomass of the spawning stock (Kjesbu et al., 1996)) and maternal effects on egg-, larval- and young fish survival (Chambers and Legget, 1996; Kjesbu et al., 1996), 
- Observations on varying growth and/or maturity ogives between year-classes (which could influence discarding rates in the commercial fishery, and a particular year-class' availability to a specific survey or fishery used for estimating abundance indices, and could also vary the level of fishing mortality associated with limit and target reference points), and knowledge about relationships determining growth and maturation (Nakken and Raknes, 1987; Campana and Hurley, 1989; Mehl and Sunnanå, 1991; Parrish and Mallicoate, 1995),

- Long time series of other data types such as CPUE or survey results (which may give a historic perspective to recruitment).

Information and knowledge as listed above, have to some extent been utilized in recent stock predictions (see e.g. Anon., MS 1997), but in general it remains to a large extent unused. Thus, the relation between fisheries science and fish stock assessments is not as simple as one might think. A main challenge is to utilize more effectively the increasing scientific knowledge of factors and relations influencing fish stock development in assessments and predictions. This will require a better communication/co-operation between fish stock assessment experts and experts working in the various fields of marine sciences.

\section{Predictive power and testability}

The problem of testability has generally not got the attention it deserves in fisheries science. The fish stock assessment tradition is characterized by abundance of quantitative short- and medium-term predictions of stock development but there is a lack of discussion of basic hypotheses underlying the predictions and their testability. The predictions often fail, and sometimes seriously, but this is usually not regarded as a problem rooted in the basic theory, but as a problem of imprecise, or lack of, key "input data". (1998):

With respect to testability, the following may be noted (a more detailed discussion is given in Ulltang

- There is a close relationship between predictive power and testability. It is always possible to construct a theory (model) which fits a certain set of observations. However, the predictive power of the theory will be small if it does not have testable consequences (there must be events which one agrees would falsify the theory), or if single ad hoc adjustments which can cause very different outcomes are allowed, thereby easily explaining very different and mutually exclusive events.

- The credibility of a complex system of theories depends on to what extent the various basic single assumptions can be tested (for example the commonly made constant suitability assumption in multispecies models). Although any attribution of falsity to any particular statement within such a system is always highly uncertain, one may sometimes be highly successful in attributing to a single hypothesis the responsibility for the falsification, and many aspects of actual methodological procedures are understandable as due to the efforts to make such attributions more successful (Popper, 1983).

- The potential of using long time series of biological and physical data in testing basic hypotheses in population dynamics has not been fully utilized.

- The extent to which events breaking a "normal" pattern can be predicted depends on to what extent the theories make testable assertions about structural and relational properties which are deeper and of a higher universality than the observed pattern of events ("appearances").

Giedymin (1960), in a paper discussing generalizations of the refutability postulate, leads the attention to what he calls a "dictatorial strategy". A dictatorial strategy is a methodological procedure where no event will be accepted as a refutation of the theory. Whatever the state of nature, the hypothesis is maintained. In addition to the trivial case where the hypothesis is an analytical statement with no observable consequences (empirical content), he lists some other situations leading to a dictatorial strategy of which the following two are of special interest in the context of fisheries science: 
1. The empirical content of the hypothesis is changed from case to case so as to make refutation impossible, for example adjust the criteria of rejection of the hypothesis to the observations.

2. The criteria of refutation of the hypothesis are to be "facts highly improbable on the hypothesis", while no definition or rule is agreed upon to make "highly improbable" an operational term, and therefore there is no determined region of rejection or the region of rejection is vague.

Spawning stock biomass-recruitment theories are examples of theories in fisheries science where dictatorial strategies have been applied to a large extent. Since the existence of a relationship between parent stock and recruitment is so critical to population stability (Rothschild, 1986), the large scatter of points around a stock-recruitment curve has in general not been taken as a refutation of the theory (situation 2. above), and several explanations have been put forward to account for the scatter. These explanations may be true, but the dictatorial strategy may be partly responsible for the fact that little attention has been paid to the basic specification of the relationship. For example, the majority of spawner-recruit relationships have used spawning biomass as the independent variable, assuming proportionality between biomass and egg production. Despite its importance this assumption is largely untested. Further, little attention has been paid to links between maternal characteristics and egg quality despite increasing knowledge of such links.

\section{The Delusion of Instrumentalism and "VPA-tuning"}

Instrumentalists interpret a scientific theory as an instrument, and nothing but an instrument, for prediction of future events. According to them, a theory should not be interpreted as a genuine conjecture about the structure of the world. The doctrine implies that scientific theories can be more or less useful (or efficient), but they can not be true or false. In contrast, realism as a philosophy assumes that we live in a real world exhibiting some kind of structural order governed by the existence of true natural laws. It is not known whether such laws can be discovered, and if discovered, their truth will not be known for certain. Although one within methodology does not have to presuppose realism, the search for causal relationships or explanations can hardly be understood without being realists (for a further discussion of instrumentalism versus realism, see Popper (1983)).

For the fish stock prediction problem, an instrumentalistic approach would be acceptable if it generally gave predictions of a sufficient reliability which could not be substantially improved by an alternative approach. However, too many predictions have in retrospect been seen to be in large error, and an instrumentalistic philosophy may partly be responsible for this. The lack of search for causal relations and explanations, concentrating the effort on the technical/mathematical aspects of the predictions, makes it too easy to accept results which, when studied in more detail, are in need for explanations.

"VPA-tuning" is a common name of methods for calibrating a traditional VPA to independent indices of stock abundance, usually catch per unit of effort data from surveys or the fishery. Various computerized procedures have been used, the most commonly used at present, at least in ICES is the XSA (Extended Survivors Analysis). There is a general lack of published literature describing the methods, but a technical description of methods as implemented in ICES is found in Darby and Flatman (1994).

The output tables giving tuning diagnostics from an XSA may be delusive in giving the impression that a comprehensive statistical analysis has been performed. However, procedures as XSA are in principle computing algorithms and not statistical models. No statistical measure of uncertainties in final results can be given. In this computing algorithm, some basic scientific assumptions are made. One such assumption is that the catchability coefficient $q$ for a given fleet/survey and age group is constant from year to year but with options as for example an allowance for making $q$ dependent on year-class strength. There is a large literature base discussing problems connected to the constant catchability assumption, but typically such problems are not discussed when applying XSA. The computing algorithm itself gives weight to the various indices according to their consistency with the VPA as calculated in each iteration. However, this may not necessarily reflect their consistency with true population numbers. That serious problems exist is illustrated by the fact that the estimated stock sizes for the same year often changes much 
from one assessment year to the next. Some problems can be illustrated by taking the ICES assessments of Northeast Arctic cod as an example. There are two reasons for selecting the cod assessments. Firstly, it is a stock of very high importance. Secondly, the technical analysis carried out by the ICES Arctic Fisheries Working Group is probably of high standard as compared to other applications of the method. For criticizing a method, one should not select an example where the technical standard is low. That would make the critique of the method weak.

XSA has been applied by the ICES Arctic Fisheries Working Group since 1993 in its assessments of the Northeast Arctic cod stock. In the 1996 assessment (Anon., MS 1997), abundance indices from 8 "fleets" (6 surveys and two commercial fleets) were used in tuning. The short text in the Working Group report explaining the assessment is symptomatic to the applications in general and may reflect an insufficient critical attitude to the method and the results. There are no serious attempts to discuss the validity of the basic assumptions or even explain why they were made. For example, in a short section describing methods for VPA and tuning, it is said that catchability was set to be stock size dependent for ages younger than 4 without any further explanation (Why not stock size dependent for older ages? What functional form for stock size dependence is assumed, and why?). In a short section describing fishing mortalities resulting from the assessment, there are two important statements. Firstly, it is said that fishing mortalities in 1991-95 was higher than calculated in last year's assessment. Secondly, it is said that the fishing mortality for 1996 is lower than estimated last year, and that the reason for this is that the 1990 and 1991 year-classes are much stronger than estimated in last year's assessment. These statements are not discussed any further.

According to what could be denoted as old stock assessment standards, the above statements would have been in need of further explanations and discussions. However, it is symptomatic of the approach that when the various outputs from one analysis are seemingly not inconsistent, further questions are not asked although basic properties of the estimation procedure are unknown and differences from earlier analyses are large. The importance of asking further questions is in this case illustrated by the following facts:

- There are now signs that the stock size was heavily overestimated by the Working Group in 1996.

- The overestimation was partly due to the catchability assumptions.

- When comparing the latest VPAs with assessments carried out during the years 1983-94, it seems that the Working Group has consistently underestimated last year's fishing mortality (Nakken, 1998).

At its meeting in August 1997 (Anon., MS 1998), the Working Group concluded that the likely stock size was much lower than estimated in 1996. From Anon (MS 1998), which became available to the author in the final stage of preparation of this paper, it is also clear that the Working Group realizes that there are severe problems with the method, and the uncertainties in the assessment and the predictions due to the problems with the assessment methodology have been more explicitly addressed in Anon (MS 1998) than in Anon (MS 1997).

It seems to be a part of the basic philosophy underlying the tuning procedures, that the more data sources one adds the more reliable will the assessment be (although a survey giving too bad tuning diagnostics may be decided to be rejected). But is that true? If for example abundance indices from two fleets are available, one giving unbiased estimates of relative abundance and the other giving biased estimates due to increase in $q$ the recent years, all would agree that including data from the second fleet would bias the stock estimates, and an assessment only using data from the first fleet might give a more reliable assessment. It may be objected that one can not see from the analysis that an abundance index is biased for the recent years, so there is no good reason to exclude it. That is exactly the point. The XSA does not show that an abundance index is biased. One needs some independent analysis and judgement of the basic data from scientists knowing fish behaviour and distribution, survey design or geographical/seasonal distribution of the fishery, recent developments in fishing gear or tactics, etc. Before computer programs for 
VPA tuning became available, scientists used more time to evaluate the different surveys and fleets from knowledge as exemplified above. The VPA was perhaps finally "manually" tuned to only one or a few series of abundance indices, following discussions of their appropriateness. Important critical discussions may have got lost when going from old "tuning" procedures to procedures such as XSA. Applying XSA does not of course preclude such discussion, it has only made it so simple to lump everything into the analysis. If such critical discussions in fact are taking place, they should be reflected in the reports. For example, going back to the report from the 1996 meeting of the Arctic Fisheries Working Group (Anon., MS 1997), there should be a discussion of why these 8 "fleets" have been included. Could for example an analysis limited to only the Norwegian Barents Sea trawl survey for certain age groups give more reliable estimates? The scientists participating in the Working Group probably possess a lot of biological knowledge and knowledge of the different fleets and surveys relevant to such a discussion. The fact that, at least to the author's knowledge, no thorough investigations of effects of erroneous indices on the whole iteration procedure have been conducted, make critical discussions of the various abundance indices particularly important.

Survey data may contain information relevant to stock assessments which is not utilized in present procedures. For example, annually repeated surveys may give estimates of total mortality coefficients which, in contrast to VPA-procedures, are independent of assumptions of natural mortality and catch statistics. These estimates can in turn be regressed against other fishery-independent information, as for example survey estimates of predator stocks or physical environmental parameters. In fact, survey based procedures may give the basis for a completely independent short-term prediction. In cases were catch statistics is dubious and/or little is known about natural mortality, these can be a useful corrective to the traditional assessment. However, usually such checks on the assessment are not carried out. Survey results are only interpreted within the narrow, and often misleading, framework of VPA tuning.

What is said above does of course not mean that we do not need population models and VPAs. These are essential tools for studying the population dynamics, stock history and long term effects of various exploitation strategies.

The instrumentalistic approach implies a degradation of discussion of biological mechanisms of relevance to stock assessments. Search for causal relationships or explanations has no significant role. In Ulltang (1996), it is argued that the overoptimistic predictions given by ICES in 1986 for the Northeast Arctic cod stock could have been avoided if species interactions and cannibalism had been taking into account, implying the unlikelihood of recruitment to the fishery of four successive strong year-classes, as the predictions assumed. It was also proposed a simple relationship, which suggestions for further development and testing, for prediction of survival from 0-group to recruitment to the fishery, taking into account the strength of preceding year-classes. In recent years, the Working Group has included cannibalism in its VPA (see Anon., MS 1997). However, the final assessment results have not been critically discussed on the background of expected effects of cannibalism. For example, the assessment given in 1996 gave a series of 7 strong or moderate year-classes at age 3 produced over the period 1989-95 (Anon., MS 1997), without discussing whether this was likely in the presence of cannibalism.

\section{What is Important to Predict, and What Knowledge is Required?}

To provide managers with the usual option tables, giving catches next year and stock size for the following year for a range of fishing mortalities is not very helpful without giving long-term consequences of the different strategies. Although short-term predictions of stock size and catches corresponding to general biological reference points as $\mathrm{F}_{\max }, \mathrm{F}_{0.1}$ and $\mathrm{F}_{\text {med }}$ may be useful, one should go a step further and for each stock try to predict long-term effects of various exploitation strategies taking into account factors such as:

- effects of exploitation on stock structure and consequences for its population dynamics

- effects of exploitation on the stock's adaptation to a fluctuating physical environment

- multispecies effects 
For example, fishing will not only reduce the size of the spawning stock, but also its composition. This may have consequences for its reproductive potential. Recent work on Northeast Arctic cod has shown that spawning biomass is not a sensitive measure of reproductive potential. Relationships between fish length, condition and fecundity results in a ratio of egg production to spawning biomass which varies both with the size composition of the spawning stock and fish condition (Marshall et al., 1997; Marshall et al., Institute of Marine Research, Norway, unpubl. MS). Condition will depend on available food resources (multispecies effects). Further, maternal effects on egg quality influencing egg- and larval-survival (Chambers and Leggett,1996; Kjesbu et al., 1996) may affect year-class strength. For Northeast Arctic cod, Marshall et al. (1997) showed that year-class strength increased with increased percentage contribution to the egg production from repeat spawners.

Also possible effects of exploitation on a stock's adaptation to a fluctuating physical environment can be illustrated by taking the Northeast Arctic cod as an example. There is a large literature base discussing periodicities in the climatic variability in the Barents Sea (see Loeng et al., 1992). There is substantial supporting evidence for the hypothesis that the different temperature regimes, characterized by cold, medium and warm climatic periods have an effect on recruitment of cod (Sætersdal and Loeng, 1987; Ellertsen et al., 1989; Nilssen et al. 1994; Ottersen et al., 1994; Ottersen and Sundby, 1995). Sætersdal and Loeng (1987) presented a hypothesis that through evolutionary processes, the reproduction is adjusted to the variations in the feeding area caused by climatic fluctuations. They note that in periods of cold climate, the feeding areas of the cod are restricted to more western and southern areas of the Barents Sea. Recruitment of rich year-classes in such periods would be a waste. After a shift from a cold to a warm period, conditions will be favourable for production of cod in a greatly expanded area of the eastern and central Barents Sea. In order to utilize this potential, there is need for high recruitment to reach these areas during the first few years of a new warm period. If the reproductive strategy of the stock is linked to periodicities in fluctuations in the physical environment through evolutionary processes as suggested by Sætersdal and Loeng (1987), effects of exploitation as for example decrease in age at maturity and decreased abundance of repeat spawners could have drastic consequences. These consequences should be predicted through simulation studies, linking hypotheses on adult mortality, growth, maturation, fecundity, maternal effects on egg- and larval survival, temperature effects on larval and young fish survival, cannibalism and periodicities in the fluctuations of the physical environment. Such simulation studies will, with the present knowledge, at least explore the room of possibilities and inherent dangers even if no firm estimates of effects can be given.

For predicting long-term effects of mechanisms as suggested above, more emphasis should be on formulating and testing basis hypothesis in population dynamics in contrast to massive data collection and following descriptive statistical analyses without any clearly defined problems and objectives. The potential of using long time series of biological and physical data in testing basic hypothesis in population dynamics has not been fully utilized. Although such series often do not contain direct observations of the parameter we are primarily interested in, more recent investigations may be used to establish relationships for estimating this parameter from the long-time observations. For example, for Northeast Arctic cod there is a long Russian time series of a liver index (liver weight divided by total weight). Recent work has established relationships between liver index, condition and fecundity (Marshall et al., Institute of Marine Research, Norway, unpubl. MS). This should make it possible to assess the long-time variations in fecundity, which in turn is essential for evaluating stock-recruitment relationships.

It has been asked whether it will be possible to process the mass of data future technology will enable scientist to collect. The question reflects an interesting and real problem, but one should for a start not assume that one has to, or should, process all those data. For improving fish stock predictions, one should go through the following steps:

i) Define the prediction problem (i.e. what are we trying to predict?)

ii) Identify crucial hypotheses on main factors determining numerical abundance and biomass of the stock in question, (i.e. hypotheses crucial for the prediction problem) 
iii) Identify the initial conditions which need to be known for carrying out the prediction (e.g. present stock size and incoming recruitment)

iv) Device methods and observations required for testing the hypotheses and estimating the initial conditions.

At stage (iv), the available observational technology and methods of processing the data needed have to be considered. New observational techniques may make it possible to test hypotheses which earlier were difficult to test, or were untestable. For example, as discussed in Ulltang (1998), techniques for studying the micro-structure of the otoliths from fish and fish larvae give quite new possibilities for testing larval and young fish survival theories by breaking a year-class into different groups of larvae which have been spawned at slightly different times and locations and follow these during the early life stages. It adds a new dimension to earlier attempts of looking at mechanisms operating on the year-class as a whole at different life stages for getting insight into recruitment functions (see for example Paulik, 1973; Rothschild, 1986; Beverton and Iles, 1992). New methods for directly observing fish behaviour during scientific surveys and catch operations (Godø, 1998) make it possible to study in more detail factors influencing fish catchability and availability to survey observations. Similarly, the development of highresolution sonars combined with new echo-sounder systems for avoiding saturation at high densities gives new possibilities for measuring the abundance of schooling fish (Misund et al., 1995). Progress in science depends on to what extent we are able to apply the various new techniques for solving basic problems in fish population dynamics and monitoring of fish abundance.

\section{Conclusion}

For improving fish stock assessments, there should be a return to fish population dynamics as an empirical science and not be limited to only an analytical system. Recent stock assessment reports are certainly more advanced from a statistical and analytical/mathematical point of view than older reports, but they often contain less natural science. An analytical/mathematical system in itself tells us nothing new about the external world, but it is an important tool for predicting consequences of the various hypotheses and for parameter estimation. The challenge is to combine this tool with new observational techniques and population dynamics thinking for testing basic hypotheses and for improving predictions of long-term effects by, for example simulation studies utilizing all available knowledge.

\section{References}

ANON. MS 1997. Report of the Arctic Fisheries Working Group. ICES C.M. Doc., No. Assess: 4, 326 p.

MS 1998. Report of the Arctic Fisheries Working Group. ICES C.M. Doc., No. Assess: 2, 366 p.

BARROS, P. 1995. Relevance of cod (Gadus morhua L.) predation for inter-cohort variability in mortality of juvenile Norwegian spring-spawning herring (Clupea harengus L.). In: Quantitative studies on recruitment variations in Norwegian spring-spawning herring (Clupea harengus Linnaeus 1758) with special emphasis on the juvenile stage. Dr. scient thesis. Department of Fisheries and Marine Biology, University of Bergen, 143 p.

BEVERTON, R. J. H., and T. C. ILES. 1992. Mortality rates of 0-group plaice (Platessa platessa L.), dab (Limanda limanda L.) and turbot (Scophthalmus maximus L.) in European waters. III. Density-dependence of mortality rates of 0-group plaice and some demographic implications. Neth. J. Sea Res., 29 (1-3): 61-79.

BOGSTAD, B., and H. GJOSFTER. 1994. A method for estimating the consumption of capelin by cod in the Barents Sea. ICES J Mar. Sci., 51: 273-280.

BOGSTAD, B., G. R. LILLY, S. MEHL, O. K. PÁLSSON, and G. STEFÁNSSON. 1994. Cannibalism and year-class strength in Atlantic cod (Gadus morhua L) in Arcto-boreal ecosystems (Barents Sea, Iceland and eastern Newfoundland). ICES Mar. Sci. Symp., 198: 576-599.

CAMPANA, S. E., and C. F. HURLEY. 1989. An age- and temperature-mediated growth model for cod (Gadus morhua) and haddock (Melanogrammus aeglefinus) larvae in the Gulf of Maine. Can. J Fish. Aquat. Sci., 46: 603613.

CHAMBERS, R. C., and W. C. LEGGETT. 1996. Maternal effects on variation in egg sizes in temperate marine fishes. American Zoologist, 36(2): 180-196.

DARBY, C. D., and S. FLATMAN. 1994. Virtual Population Analysis: version 3.1 (Windows/DOS) user guide. Information technology series no. 1, MAFF, Lowestoft. 
DERISO, R.B., T. J. QUINN, and P. R. NEAL. 1985. Catch-age analysis with auxiliary information. Can. J Fish. Aquat. Sci., 42(4): 815-824.

DICKSON, R. R., K. R. BRIFFA, and T. J. OSBORN. 1994. Cod and climate: the spatial and temporal context. ICES Mar. Sci. Symp., 198: 280-286.

ELLERTSEN, B., P. FOSSUM, P. SOLEMDAL, and S. SUNDBY. 1989. Relation between temperature and survival of cod eggs and first feeding larvae of Northeast Arctic cod (Gadus morhua L.). ICES Rapp. Proc.-Verb., 191: $209-219$.

GIEDYMIN, J., 1960. A Generalization of the Refutability Postulate. Studia Logica, 10: 97-108.

GODØ, O. R. 1998. What can technology offer the future scientist - possibilities for obtaining better estimates of fish stock abundance by observations from the sea. J. Northw. Atl. Fish. Sci., 23: 105-131 (this volume).

KJESBU, O. S., P. SOLEMDAL, P. BRATLAND, and M. FONN. 1996. Variation in annual egg production in individual captive Atlantic cod (Gadus morhua). Can. J Fish. Aquat. Sci., 53(3): 610-620.

LOENG, H., J. BLINDHEIM, B. ÅDLANDSVIK, and G. OTTERSEN. 1992. Climatic variability in the Norwegian and Barents Seas. ICES Mar. Sci. Symp., 195: 52-61.

MARSHALL, C. T., O. S. KJESBU, P. SOLEMDAL, Ø. ULLTANG, and N. A. YARAGINA. 1997. Betydningen av eggproduksjon for årsklassevariasjon hos norsk-arktisk torsk. Havforskningsinstituttet. Fisken og Havet, Særnummer, 2: 68-72 (in Norwegian).

MEHL, S., and K. SUNNANA. 1991. Changes in growth of Northeast Arctic cod in relation to food consumption in 1984-1988. ICES Mar. Sci. Symp., 193: 109-112.

MISUND, O. A., A. Aglen, and E. FRONÆS. 1995. Mapping the shape, size, and density of fish schools by echo integration and a high-resolution sonar. ICES J. Mar. Sci., 52: 11-20.

NAKKEN, O. 1998. Past, present and future exploitation and management of marine resources in the Barents Sea and adjacent areas. Fish. Res., (in press).

NAKKEN, O., and A. RAKNES. 1987. The distribution and growth of Northeast Arctic cod in relation to bottom temperatures in the Barents Sea, 1978-1984. Fish. Res., 5: 243-252.

NILSSEN, E. M., T. PEDERSEN, C. C. E. HOPKINS, K. THYHOLT, and J. G. POPE. 1994. Recruitment variability and growth of Northeast Arctic cod: Influence of physical environment, demography, and predator - prey energetics. ICES Mar. Sci. Symp., 198: 449-470.

OTTERSEN, G., H. LOENG, and A. RAKNES. A. 1994. Influence of temperature variability on recruitment of cod in the Barents Sea. ICES Mar. Sci. Symp., 198: 471-481.

OTTERSEN, G., and S. SUNDBY. 1995. Effects of temperature, wind and spawning stock biomass on recruitment of Arcto-Norwegian cod. Fish. Ocean., 4(4): 278-292.

PARRISH, R. H., and D. L. MALLICOATE. 1995. Variation in the condition factors of California pelagic fishes and associated environmental factors. Fish. Ocean., 4(2): 171-190.

PAULIK, G. J. 1973. Studies of possible forms of the stock-recruitment curve. ICES Rapp. Proc.-Verb., 164: $303-315$.

POPE, J. G. 1972. An investigation of the accuracy of Virtual Population Analysis using Cohort Analysis. ICNAF Res. Bull., 9: 65-74.

POPE, J. G., and J. G. SHEPHERD. 1982. A simple method for the consistent interpretation of catch-at-age data. ICES J. Cons., 40: 176-182.

POPPER, K. R. 1983. Realism and the aim of Science. From the Postscript to the Logic of Scientific Discovery. W. W. Bartley, III (ed). Routledge 1992, 420 p.

ROTHSCHILD, B. J. 1986. Dynamics of Marine Fish Populations. Harvard University Press, 277 p.

SCHNUTE, J. T. 1994. A general framework for developing sequential fisheries models. Can. J Fish. Aquat. Sci., 51(8): 1676-1688.

SHEPHERD, J. G., J. G. POPE, and R. D. COUSENS. 1984. Variation in fish stocks and hypotheses concerning links with climate. ICES Rapp. Proc.-Verb., 185: 255-267.

SÆTERSDAL, G., and H. LOENG. 1987. Ecological adaptations of reproduction in Northeast Arctic cod. Fish. Res., 5: $253-270$.

ULLTANG, Ø. 1977. Sources of errors in and limitations of Virtual Population Analysis (Cohort Analysis). ICES J. Cons., 37(3): 249-26.

1996. Stock assessment and biological knowledge: can prediction uncertainty be reduced? ICES J. Mar. Sci., 53: 659-675.

1998. Explanations and predictions in fisheries science - problems and challenges in a historical and epistemological perspective. Manuscript submitted to Proceedings of Fisheries Management under Uncertainty Symposium, Bergen 3-5 June 1997. Fish. Res., (in press). 
